\title{
LOS ESTUDIOS EPIGRÁFICOS DESDE LA TEORÍA DE LA COMUNICACIÓN: EL FRISO DE LA CAPILLA DEL COLEGIO DE SAN GREGORIO DE VALLADOLID
}

\section{A VISION OF EPIGRAPHY IN LIGHT OF THE THEORY OF COMMUNICATION: THE FRIEZE OF THE CHAPEL OF ST. GREGORY'S COLLEGE IN VALLADOLID}

\author{
FRANCISCO J. MOLINA DE LA TORRE \\ Universidad de Valladolid
}

\begin{abstract}
Resumen: A lo largo de los siglos las inscripciones han sido herramientas indispensables a la hora de transmitir un mensaje a una audiencia lo más amplia posible. En la actualidad los estudiosos subrayan la naturaleza comunicativa de las inscripciones. Por ello, este estudio pretende contemplar la epigrafía a la luz de las modernas teorías de la comunicación. La existencia de tres factores fundamentales - subjetivos, objetivos y práxicos- en el proceso de comunicación (según la propuesta del profesor Martín Algarra) constituye el fundamento de este artículo. Este marco teórico viene seguido del pormenorizado análisis de un ejemplo: el friso de la capilla del Colegio de San Gregorio de Valladolid. Esta larga inscripción ilustra a la perfección las cuestiones tratadas en la primera parte: los diferentes actores implicados en el acto de comunicación, los elementos objetivos de la inscripción y las acciones necesarias para expresar el mensaje y para interpretarlo a lo largo del tiempo.

Palabras clave: Epigrafía. Inscripción. Comunicación. Alonso de Burgos. Colegio de San Gregorio. Valladolid.
\end{abstract}

\begin{abstract}
For centuries, inscriptions have been key instruments in the process of conveying a message to a wide audience. Today's scholars underscore the communicative nature of inscriptions. Therefore, this paper is an attempt to see epigraphy in light of the modern theories of communication. The existence of three basic factors - subjective, objective, and pragmatic - in the process of communication (according to Martín Algarra's proposal) constitutes the basis for the present work. This theoretical framework is then followed by a case study: the frieze of the chapel of St. Gregory's College in Valldolid. The long inscription carved in it becomes a perfect example of the issues we consider in the first section of the article: the different actors involved in the act of communication, the objective elements of the inscription, and the actions needed in order to express the intended message and to interpret it throughout the centuries.
\end{abstract}

Keywords: Epigraphy. Inscription. Communication. Alonso de Burgos. St. Gregory's College. Valladolid. 
Hace algunos años se reabrió al público tras una larga restauración el Museo Nacional de Escultura de Valladolid. El edificio es uno de los más conocidos ejemplos del llamado gótico isabelino, desarrollado a finales del siglo XV y comienzos del XVI. Fue el obispo de Palencia, fray Alonso de Burgos, quien encargó la construcción del colegio, comenzando por la que sería capilla funeraria del mecenas. En ella colocó una larga inscripción que sirve al prelado para dar a conocer tanto su obra como su persona. Teniendo en cuenta la naturaleza del epígrafe como medio de comunicación, el objeto del presente trabajo es analizar la inscripción de una forma integral a la luz de las modernas teorías de la comunicación. Esta lectura cobra mayor importancia si consideramos que los actuales estudios respecto al edificio siguen basándose en la lectura errónea que en su día realizó fray Domingo Díaz, y que ha obligado a plantearse diversas hipótesis en torno, sobre todo, a la fecha de inicio de las obras.

\section{LA EPIGRAFÍA DESDE LA TEORÍA DE LA COMUNICACIÓN.}

La relación entre epigrafía y comunicación es un hecho probado. Así, la definición de epigrafía que propone Favreau al comienzo de su Épigraphie médiévale sostiene que esta estudia aquello que está escrito "a fin de comunicar alguna información", lisis del tema, llegando a afirmar que es "el 'medio de comunicación publicitaria' por excelencia, único hasta la aparición de la moderna publicidad a partir de la difusión de la imprenta"2. Por ello nos parece que los actuales planteamientos sobre el tema de la comunicación pueden ser un campo fértil para llevar a cabo una reflexión general sobre la epigrafía.

Dada la peculiar naturaleza del epígrafe como medio de comunicación, creemos que la propuesta planteada por Manuel Martín Algarra ${ }^{3}$, basada en los planteamientos fenomenológicos de Edmund Husserl y Alfred Schutz, permite una lectura muy enriquecedora de las inscripciones a la luz de la teoría de la comunicación. Distingue Martín Algarra tres grandes elementos que integran necesariamente todo proceso comunicativo: los subjetivos, los objetivos y los práxicos.

Lo habitual, en los distintos modelos de teoría de la comunicación, es distinguir entre quien está en el punto de origen y quién está en el punto final del

\footnotetext{
${ }^{1}$ R. FAVREAU, Épigraphie médiévale, Turnhout, 1997, p. 5.

${ }^{2}$ V. GARCÍA LOBO, "La catedral de León, centro de producción publicitaria", en Congreso internacional "La Catedral de León en la Edad Media”, León, 2004, p. 59.

${ }^{3}$ M. MARTÍN ALGARRA, Teoría de la comunicación: una propuesta, Madrid, 2003.
} 
proceso de comunicación, hablándose de "emisor" y "receptor", de "destinador" y "destinatario", etc. Martín Algarra integra todo ello en la categoría de elementos subjetivos de la comunicación y habla de "actores". A su juicio, las divisiones mencionadas se basan en criterios funcionales que no siempre se adecuan a la realidad. En ese sentido, la figura del llamado "rogatario" es paradigmática: en el proceso de comunicación, ¿cuál es su función? ¿Ha de considerársele emisor de un texto o receptor del mensaje que desea transmitir quien solicita el escrito? En realidad, es ambas cosas, por lo que una misma persona habría de ser considerada desde dos funciones diversas.

El segundo tipo de elementos que considera Martín Algarra son los que denomina "objetivos". Según él, "podemos referirnos a tres tipos de realidades que se transmiten en el proceso comunicativo: el referente real, el referente mental y el producto apresentador" ${ }^{4}$. El referente real remite al acontecimiento, el objeto o la idea que desea darse a conocer mediante el proceso comunicativo. Prácticamente todo epígrafe está en conexión, si bien normalmente indirecta, con uno o varios referentes reales, ya sea el fallecimiento de una persona, la construcción de un edificio o el traslado de unos restos. La excepción la constituyen aquellos epígrafes que dan noticias falsas o que informan de algo que jamás existió o sucedió. Es el caso de los falsos, ciertamente mucho menos frecuentes en epigrafía que en paleografía 5 .

El referente mental "es el referente real en cuanto que conocido", en tanto que objeto de la conciencia. Nuestro acceso a la realidad no es directo, sino mediado por una serie de condiciones previas, pues cada persona se sitúa en la vida de una forma determinada, de acuerdo con lo que Schutz denomina "situación biográfica" ". Paulatinamente los estudios de historia han comenzado a tener en cuenta este aspecto, tal como pone de manifiesto la "historia de las mentalidades". En relación con la epigrafía, la variación en el referente mental permite explicar que una misma realidad quede reflejada de forma diversa en distintos epígrafes. Por ejemplo, como veremos más adelante, desde esta perspectiva podemos considerar las notables diferencias que muestran dos epígrafes que, en el fondo, remiten a un mismo referente real: la construcción de un edificio.

\footnotetext{
${ }^{4}$ M. MARTÍN ALGARRA, Teoría de la comunicación..., p. 129.

5 Por ejemplo, A. DURÁN GUDIOL, "Las inscripciones medievales de la provincia de Huesca", Estudios de Edad Media de la Corona de Aragón, 8 (1967), pp. 67-68, saca a la luz una serie de "falsificaciones epigráficas" procedentes del monasterio de San Juan de la Peña.

${ }^{6}$ M. MARTÍN ALGARRA, Teoría de la comunicación..., p. 130.

${ }^{7}$ A. SCHUTZ, El problema de la realidad social, Buenos Aires, 1974, pp. 137-138.
} 
El "producto apresentador" lo define Martín Algarra como "el objeto que el actor produce para significar lo que desea expresar, lo que ha conocido como fruto

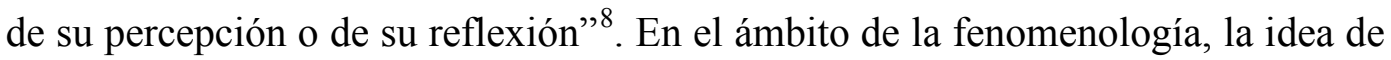
apresentación remite a la experiencia de algo que, a su vez, apunta hacia otra realidad que no es percibida de manera directa. Por ejemplo, al contemplar un objeto lo que aprehendemos directamente de él no es sino una faceta, si bien inmediatamente incluimos otros aspectos que no están presentes en la percepción primera. Así, considerar el epígrafe como producto apresentador nos permite dotar de sentido a un objeto cuyo referente real ha podido desaparecer, como, por ejemplo, una placa conservada en un museo que deja constancia de la construcción de cierto edificio arruinado hace años.

Finalmente, la propuesta del profesor navarro incluye los elementos práxicos, a saber, la expresión y la interpretación. La expresión, entendida como "acción significativa que tiene como finalidad manifestar lo que se piensa o se siente" ${ }^{\text {, }}$, remite a todas las acciones que llevan a cabo los actores para dar a conocer determinados acontecimientos, ideas, experiencias, etc. A la luz de la epigrafía, aquí deberíamos considerar aquellos elementos que forman parte de lo que en diplomática se conoce como conscriptio ${ }^{10}$.

El segundo elemento práxico que contempla Martín Algarra es la interpretación. A nosotros nos interesa particularmente lo que afirma en relación con la "interpretación de la expresión social"11. En nuestro caso, no se trata meramente de interpretar el mensaje que nos presenta cualquier epígrafe. Es preciso también indagar, en la medida de lo posible, lo que ha motivado su confección y su transmisión. Toda inscripción, antes de llegar a nosotros, ya ha sido objeto de innumerables interpretaciones tanto correctas como incorrectas, algunas de las cuales han dejado huella importante. De hecho, la inscripción casi nunca llega a nosotros de

\footnotetext{
${ }^{8}$ M. MARTÍN ALGARRA, Teoría de la comunicación..., p. 131.

${ }^{9}$ M. MARTÍN ALGARRA, Teoría de la comunicación..., p. 144.

${ }^{10}$ En el mundo de la diplomática la conscriptio se define como "la consignación por escrito de esa acción (la actio), con sus derechos y obligaciones" (T. MARÍN MARTÍNEZ - J. M. RUIZ ASENCIO, Paleografía y diplomática, vol. II, $5^{\text {a }}$ ed., Madrid, 1995, p. 164). Por su parte, V. GARCÍA LOBO - M. E. MARTÍN LÓPEZ, De epigrafía medieval. Introducción y álbum, León, 1995, pp. 28-30, hablan de conscriptio epigraphica, es decir, de "la materialización del mensaje epigráfico", pasando revista a los distintos momentos que, a su juicio, integran el proceso: minuta, ordinatio e incisio.

${ }^{11}$ M. MARTÍN ALGARRA, Teoría de la comunicación..., p. 154.
} 
una forma inmediata, sino mediada por anteriores interpretaciones. Aquí cabría hablar, como hacen García Lobo y Martín López, de "tradición epigráfica"12.

\section{LA INSCRIPCIÓN DE LA CAPILLA DEL COLEGIO DE SAN GREGORIO DE VALLADOLID.}

En esta segunda parte de nuestro trabajo pretendemos clarificar el planteamiento teórico que acabamos de exponer aplicándolo a un ejemplo concreto de la epigrafía medieval vallisoletana: la inscripción situada en el friso de la capilla del Colegio de San Gregorio de Valladolid ${ }^{13}$, actualmente ocupada por el Museo Nacional de Escultura.

Sin duda, se trata de un texto por medio del cual quien lo encargó deseaba transmitir un mensaje que consideraba importante. Nuestra labor ahora es examinar quiénes están implicados en el proceso comunicativo del que la inscripción forma parte (elementos subjetivos), qué es aquello que se quiere transmitir (elementos objetivos) y qué mecanismos emplean tanto quienes lo formulan cuanto quienes lo interpretan (elementos práxicos).

\subsection{Elementos subjetivos.}

En el origen de toda inscripción se halla la voluntad de una persona o comunidad que desea transmitir un mensaje. En el caso de la epigrafía medieval, en las más antiguas inscripciones se da prioridad a la labor realizada, mientras que "el patrocinador queda en un segundo plano frente a la obra" ${ }^{14}$. Paulatinamente va a ser este quien reciba una mayor atención, convirtiéndose la inscripción en un medio de promoción de quien encarga la obra. Dentro de este segundo tipo podemos incluir el epígrafe que ahora estudiamos, donde resalta especialmente el promotor: "el muy rreverendo e muy magnífico señor el señor don Alfonso de Bur-

${ }^{12}$ V. GARCÍA LOBO - M. E. MARTÍN LÓPEZ, De epigrafía medieval..., pp. 41-43; V. GARCÍA LOBO, "La epigrafía medieval. Cuestiones de método", en Centenario de la Cátedra de Epigrafía y Numismática, Universidad Complutense de Madrid, 1900/01-2000/01, Madrid, 2001, pp. 101-103.

${ }^{13}$ Para todos los aspectos relacionados con el colegio, resulta fundamental la historia que escribió fray Gonzalo de Arriaga a mediados del siglo XVII, la cual ha sido publicada por M. HOYOS, Historia del Colegio de San Gregorio de Valladolid, 2 vols., Valladolid, 1928, 1930. Además, se conserva tanto el Libro Becerro del Colegio de San Gregorio compuesto por fray Vicente Velázquez en 1769 (Archivo Histórico Nacional [AHN], Códices, libro 1260) como documentación de muy diversa índole (AHN, Clero, leg. 2298).

${ }^{14}$ R. FAVREAU, Épigraphie médiévale, p. 114. 


\section{FRANCISCO J. MOLINA DE LA TORRE \\ LOS ESTUDIOS EPIGRÁFICOS DESDE LA TEORÍA DE LA COMUNICACIÓN}

gos, obispo de Palencia, conde de Pernía”. Tanto su vida cuanto su actividad como mecenas ha sido estudiada en diversas ocasiones ${ }^{15}$, por lo que aquí nos concentraremos en aquellos datos que se desprenden del epígrafe que mandó colocar en el friso de la capilla que dispuso para sepultura suya.

El tratamiento de "muy reverendo y muy magnífico señor" se dispensaba en aquellos momentos, entre otras dignidades, al obispo. El nombre de Alonso de Burgos deriva probablemente del lugar de su nacimiento, la serranía de la Mortera, enclavada entonces en el norte del obispado de Burgos y perteneciente hoy a Cantabria. También al lugar de nacimiento se debe muy posiblemente el mote de fray Mortero con el que se le conocía entonces ${ }^{16}$, si bien hay quien lo atribuye a otros motivos ${ }^{17}$. Fue nombrado obispo de Palencia el 26 de agosto de 1485, tras ejercer el episcopado en Córdoba (1477-1482) y Cuenca (1484-1485). Se conserva una breve descripción de la entrada del obispo en Palencia atribuida al canónigo Juan de $\operatorname{Arce}^{18}$. Como obispo de Palencia recibió el título de conde de Pernía, pues desde 1410, en virtud de la merced que el rey Juan II hizo al obispo Sancho de Rojas por los servicios que éste le prestó en el cerco de Antequera, ambos cargos estaban vinculados ${ }^{19}$.

No son estas las únicas noticias que la inscripción nos da de fray Alonso de Burgos, pues más adelante, tras mencionar a los reyes, dice: "cuya fechura e crianca e capellán mayor e confesor él es". Algo parecido encontramos en su testamento, donde declara: "Otrosí, por cuanto Nos habemos seido e somos fechura e criatura de la rreina, nuestra Señora, y en este mundo nunca otra cosa amamos ni

${ }^{15}$ C. J. ARA GIL, "La actividad artística en la catedral de Palencia durante los obispados de Diego Hurtado de Mendoza y Fray Alonso de Burgos", en Jornadas sobre la Catedral de Palencia, Palencia, 1989, pp. 67-97; J. URREA FERNÁNDEZ, "Fray Alonso de Burgos y el Colegio de San Gregorio", en Arte y mecenazgo, Valladolid, 2000, pp. 9-32; J. I. HERNÁNDEZ REDONDO, "Aportaciones al estudio del legado artístico de Fray Alonso de Burgos", en Imágenes y promotores en el arte medieval. Miscelánea en homenaje a Joaquín Yarza Luaces, Bellaterra, 2001, pp. 423-439.

${ }^{16}$ Según Gonzalo Fernández de Oviedo, Batallas y Quinquagenas, Madrid, 2000, libro III, 21, en las llamadas Coplas del Provincial se incluía la siguiente: "Cárdenas y el Cardenal, Chacón e Fray Mortero, traen la corte al retortero". No obstante, esta estrofa no aparece en el manuscrito (ms. 354) conservado en el fondo español de la Biblioteca Nacional de París.

${ }^{17}$ Por ejemplo, A. ÁLVAREZ REYERO, Crónicas episcopales palentinas, Palencia, 1898, p. 200, afirma que se debe a "su pasión por las Bellas Artes". Por su parte, A. COTARELO VALLEDOR, Memoria biográfica de Fray Diego de Deza, y noticia de su influencia en el descubrimiento de América, Madrid, 1905, p. 127, considera que el mote deriva de la figura rechoncha y escasa inteligencia del obispo.

${ }^{18}$ El texto lo transmite M. HOYOS, Historia del Colegio..., vol. I, p. 26.

${ }^{19}$ A. FERNÁNDEZ DE MADRID, Silva palentina, ed. J. San Martín Payo, Palencia, 1976, p. 272. 
quisimos que el servicio de Su Alteza y el alongamiento e conservación de su muy preciosa vida, etc." ${ }^{20}$.

La presencia de Alonso de Burgos en el círculo más cercano de Isabel está documentada antes de 1479; ya la crónica de Enrique IV de Castilla nos recuerda con cierto desprecio que "era asymesmo en su consejo fray Alonso de Burgos, de la Orden de los Predicadores, onbre menos çiente de quanto convenía para el lugar donde estava"21. La misma crónica nos permite conocer que ya en 1473 era capellán mayor, pues relata un altercado que se produjo entre fray Alonso de Burgos y Alarcón, hombre de confianza del arzobispo de Toledo, a consecuencia del cual, “con gran enojo que la princesa ovo, mandó a fray Alonso que por çiertos días no entrase en palaçio" ${ }^{22}$. Incluso tras la muerte del prelado palentino, la reina Isabel, a la que fray Alonso de Burgos nombró patrona de su fundación, escribe: "Por cuanto don Alonso de Burgos, obispo que fue de Palencia, mi capellán mayor, del mi consejo..."23. Llama la atención, sin embargo, el hecho de que la inscripción no incluya la mención de que fray Alonso era del consejo de los reyes, algo que es perfectamente conocido y que aparece con frecuencia en la documentación ${ }^{24}$.

Así, el primero de los elementos subjetivos en el proceso de comunicación es fray Alonso de Burgos. Sin embargo, su deseo de construir la capilla no es sino el primer paso de todo el complejo a estudiar. Las inscripciones medievales no son textos aislados, sino que forman parte de una obra más amplia de la que dan razón o a la que tratan de explicar, con la cual forman un todo ${ }^{25}$. Los autores de esas obras son llamados "artistas" por Favreau ${ }^{26}$. El término hoy generalizado de "artista", aunque válido, ha de ser interpretado rectamente, pues, como Yarza Luaces pone de manifiesto, "el nombre que les corresponde a todos estos persona-

\footnotetext{
${ }^{20}$ El testamento lo reproduce M. HOYOS, Historia del Colegio..., vol. I, pp. 113-136 (la frase citada, procedente del artículo XXIX, aparece en la p. 131).

${ }^{21}$ M. P. SÁNCHEZ-PARRA, Crónica anónima de Enrique IV de Castilla (1454-1474). Crónica castellana, Madrid, 1991, p. 275.

${ }^{22}$ M. P. SÁNCHEZ-PARRA (ed.), Crónica anónima..., p. 414.

${ }^{23}$ La cédula de Isabel la incluye M. HOYOS, Historia del Colegio..., vol. I, pp. 138-145.

${ }^{24}$ Por ejemplo, Archivo General de Simancas (AGS), Registro General del Sello (RGS), septiembre de 1498, doc. 187; AGS, Patronato Real, leg. 32, doc. 10.

${ }^{25}$ De ello se sigue que no resulta conveniente atender al epígrafe en sí, ignorando el entorno en el que aparece. Algo así intuía J. M. de NAVASCUÉS y de JUAN, El concepto de la epigrafía. Consideraciones sobre la necesidad de su ampliación, Madrid, 1953, pp. 65-66, al sostener que "la inscripción es, pues, como todo escrito, un cuerpo físico en el cual se funden en un solo ser la escritura y su soporte, el cual es a su vez, la expresión plástica de un lenguaje y de un pensamiento". En cualquier caso, probablemente Navascués todavía limitaba la idea del soporte a un elemento físico concreto, sin considerar la obra en su conjunto.

${ }^{26}$ R. FAVREAU, Épigraphie médiévale, pp. 124-126.
} 
jes es el de artesano"27. ¿Conocemos la identidad de los artistas que trabajaron en la capilla del colegio de San Gregorio? Curiosamente sabemos quiénes fueron contratados por el obispo palentino debido a que no realizaron un buen trabajo y el prelado tuvo que acudir a los reyes, quienes por medio de una provisión real fechada el 4 de diciembre de 1488 encomendaron a los alcaldes de casa y corte resolver el litigio:

Fernando de Saavedra, en nombre del rreverendo en Christo padre obispo de Palencia, nos fizo relación de su petición que ante nos en el nuestro consejo presentó diciendo que el dicho obispo se convino con Juan Guas e Juan de Talavera, canteros, para que ellos fiziesen a destajo una capilla de cal y canto con su tribuna y estrivos... ${ }^{28}$.

Juan Guas y Juan de Talavera son, por tanto, los artistas responsables de la obra en la que se enmarca nuestra inscripción. La figura de Juan Guas resulta bien conocida $^{29}$, y sabemos que trabaja en San Gregorio al mismo tiempo que en Olmedo y Segovia. De hecho, en el libro de fábrica de la catedral segoviana correspondiente al año 1487, se anota lo siguiente a finales del mes de septiembre: "A Juan Guas, de sus jornales de tres días de la venida y quatro me contó quando vino a faser abrir la claraboya e truxo a Pedro de Toledo e Grabriel, entalladores, e de quando vino de Valladolid, que son siete días... CCCL mrs" ${ }^{30}$. Por su parte, la obra del "entallador" Juan de Talavera ha sido menos estudiada, aunque hay suficiente documentación para afirmar que la relación entre ambos maestros se remonta al menos a $1477^{31}$. Al mismo tiempo debía trabajar en la obra de la Mejorada en Olmedo, pues en dicho libro de fábrica, correspondiente a la tercera semana de octubre, se anota: "el dicho Juan de Talavera, entallador, que vido de la Mejorada, de dos días que labró XC mrs"32.

Al comparar las inscripciones que aparecen en las diversas obras dirigidas por el maestro Guas hemos de concluir que no era él quien grababa la inscripción

\footnotetext{
27 J. YARZA LUACES, “Artista-artesano en la Edad Media hispana”, en L'artista-artesà medieval a la Corona d'Aragó, Lleida, 1999, p. 9.

${ }^{28}$ AGS, RGS, diciembre de 1488, doc. 131.

${ }^{29}$ Para una breve biografía, cf. J. M. de AZCÁRATE RISTORI, La arquitectura gótica toledana del siglo XV, Madrid, 1958, pp. 17-26; ID., "Unos documentos sobre Juan Guas", Boletín del Seminario de Estudios de Arte y Arqueología, 26 (1960), pp. 239-257. También es sumamente interesante, sobre todo respecto a los sueldos y las diversas obras que compaginaba, la investigación de A. HERNÁNDEZ, "Juan Guas. Maestro de obras de la catedral de Segovia (1472-1491)", Boletín del Seminario de Estudios de Arte y Arqueología, 13 (1946-1947), pp. 57-100.

${ }^{30}$ A. HERNÁNDEZ, "Juan Guas...", p. 97.

${ }^{31}$ A. HERNÁNDEZ, “Juan Guas...”, p. 90.

${ }^{32}$ A. HERNÁNDEZ, “Juan Guas...”, p. 90.
} 
en la piedra. Hay notables diferencias entre los epígrafes que se conservan, por ejemplo, en San Juan de los Reyes de Toledo, en el Palacio del Infantado de Guadalajara y en la capilla del Colegio de San Gregorio de Valladolid. Por ello, como es lógico, hemos de postular la existencia de otros artesanos dedicados a la realización de estas inscripciones. Se trataría de personajes anónimos a los que, a la luz de los estudios de Mallon y Susini, denominamos ordinator y lapicida. Del primero apenas es posible decir nada; su labor ha quedado oculta tras la mano de quien llevó a cabo la incisión y la pintura de las letras. Tal vez lo único que podemos deducir es que su conocimiento del latín no sea demasiado bueno, lo que le lleva a cometer algunos errores en la disposición del texto, como más adelante veremos.

Elementos subjetivos son también aquellos que se sitúan en el otro extremo del proceso comunicativo. Se ha insistido repetidamente en el carácter universal de la inscripción, afirmándose que esta tiene por objeto ser leído por el mayor número de público posible. No obstante, es preciso recordar que el promotor, al encargar la elaboración de una inscripción, pensaba en un grupo más o menos concreto de destinatarios ${ }^{33}$.

En ese sentido, los estudios sobre el mundo de la comunicación hablan del destinatario o receptor intencional ${ }^{34}$. En el caso de la inscripción de la capilla de San Gregorio los destinatarios están explícitamente indicados: "los colegiales deste colegio e capellanes de su capilla”. En virtud de la bula de fundación otorgada por Inocencio VIII el 15 de diciembre de 1487, el papa concede a Alonso de Burgos la facultad de erigir un colegio en el que dieciséis hermanos de la orden de predicadores se dedicaran al estudio. Poco después, el 9 de septiembre de 1488 el mismo pontífice permite que el número aumente hasta veinte colegiales (ut sibi quod numerum praedictum sexdecim fratrum usque ad numerum viginti augere possit). En los estatutos del colegio, con fecha de 3 de noviembre de 1499, fray Alonso explicita quiénes han de ser dichos colegiales, en particular en lo referente a su número ${ }^{35}$.

${ }^{33}$ L. MARTÍNEZ ÁNGEL, Inscripciones medievales de la provincia de Segovia, León, 2000, p. 42; V. DEBIAIS, Messages de pierre, Turnhout, 2009, p. 247-292.

${ }^{34}$ D. K. BERLO, El proceso de la comunicación. Introducción a la teoría y a la práctica, $2^{\mathrm{a}}$ ed., Buenos Aires, 2000, pp. 12-16.

${ }^{35}$ M. HOYOS, Historia del Colegio..., vol. I, p. 103: "Otrosí conformándonos con las Bulas e Facultades Apostólicas que para esto tenemos, estatuimos y ordenamos, que así de dicha Casa e Colegio estén o residan veinte frailes de observancia de la Orden de Santo Domingo, nombrados colegiales [...] De el monasterio de San Pablo de Burgos, dos frailes, que sean hijos naturales de dicha casa; y otros dos, de el monasterio de San Pablo de Córdoba, donde primeramente fuimos obispo; y otros dos, de la ciudad de Cuenca o de su diócesis, donde, desde Córdoba, fuimos trasla- 
Además de los colegiales, el papa Alejandro VI concedió una bula facultando al obispo a fundar doce capellanías ${ }^{36}$. Como nos refiere el Libro Becerro, "el año de 1489, concluida dicha capilla, fundó su Illustrísima ciertas capellanías para cuio cumplimiento nombró doze capellanes, y hizo ciertas ordenaciones mui utiles para su conservazión, y por la ordenación octava les manda a dichos capellanes que sean obligados a zelebrar y decir en la dicha su capilla seis misas cada día, y una de ellas ha de ser cantada a la ora del Alba, y asimismo por la ordenación nona les manda que digan en su capilla todas las oras canónicas en esta forma: a el amanecer digan los maitines en tono y acavados canten la prima y tercia, y luego digan la misa mayor cantada, y después vaian todos a decir un responso sobre su sepoltura, y después digan la sexta y nona cantadas, distribuiendo las oras de modo que no impidan los oficios divinos que se zelebran en el Combento de San Pablo" 37 . Un resumen de estas disposiciones es lo que encontramos grabado en la inscripción que corona la capilla: "para que los colegiales deste colegio e capellanes de su capilla celebren las misas e digan las oras canonicas". En cualquier caso, tras la muerte del fundador no tardaron en suscitarse conflictos diversos entre colegiales y capellanes, que provocaron en 1502 la expulsión de estos últimos ${ }^{38}$.

Sin duda, fray Alonso de Burgos pensaba fundamentalmente en ellos al redactar el epígrafe, pero no fueron los únicos que lo vieron. En su estudio de la comunicación $^{39}$, David Berlo plantea la existencia de unos receptores intenciona-

dado; y otros dos, de el monasterio de la ciudad de Palencia, donde agora somos obispo; y otros dos, de el monasterio de San Pablo de esta villa de Valladolid; y de el monasterio de la ciudad de Toro, uno; y de la ciudad de Zamora, otro; y de el monasterio de Medina del Campo, otro; de el monasterio de Segovia, otro; de el monasterio de Ávila, otro; y de el monasterio de la ciudad de Toledo, otro; y del reino de Galicia, otro; y del Extremadura, otro; del Andalucía, otro; del Reino de Granada, otro. Así, que cumplidos los dichos veinte frailes, de este número uno ha de ser rector de dicho colegio y tres consiliarios".

${ }^{36}$ El Libro Becerro del Colegio de San Gregorio (f. 376) resume su contenido de la manera siguiente: "Ytem otra del mismo [Alejandro VI] dada en 8 de Enero de 1498 da facultad para fundar en el Collegio 12 capellanías y quatro acólitos y para que los capellanes residiendo aquí pudiesen percibir la renta de otros qualesquier veneficios que obtubiesen".

${ }^{37}$ AHN, Códices, libro 1260, f. 264.

${ }^{38}$ La historia de Arriaga incluye una carta de Diego de Deza, fechada el 20 de julio de 1502 , en la que leemos lo siguiente: "Así por estas causas, como por otras muchas, que a ello nos mueven, por la Autoridad Apostólica a Nos concedida, de que en esta parte usamos, e por el parescer e consentimiento que nos dio la Reina, nuestra señora, por virtud del dicho Breve Apostólico de suso incorporado, en la mejor forma que de derecho debemos; quitamos e amovemos al Capellán mayor e capellanes e mozos de Capilla de la dicha Capilla e los privamos desde agora, e por la presente habemos por privados, de sus Capellanías e oficios, que en la dicha Capilla tenían, e de todos los títulos, derechos e astienes [lege actiones] que a las dichas Capellanía e oficios les pertenezca" (M. HOYOS, Historia del Colegio..., vol. I, p. 158).

${ }^{39}$ D. K. BERLO, El proceso de la comunicación..., p. 13. 
les y otros no intencionales, y creemos que es una distinción adecuada también para el mundo de la epigrafía. Además de los capellanes y colegiales, desde muy temprano hubo reacciones positivas entre quienes contemplaron la inscripción del obispo de Palencia, pues cuando en 1498 el mercader Luis de la Serna contrata con Juan de Arandia la construcción de la capilla mayor de la parroquia de Santiago Apóstol especifica que la inscripción que se realice ha de imitar la de la capilla de Alonso de Burgos ${ }^{40}$. De receptores no intencionales hemos de calificar indudablemente a las tropas francesas que allí se asentaron durante los años que duró la guerra de la independencia ${ }^{41}$. Además, tampoco eran los destinatarios de la inscripción quienes trabajaron en la capilla, consagrada a lo largo del siglo XIX a muy diversos usos, pues el colegio, "en manos del Estado, pasó por los más diversos destinos: fue Gobierno Civil, Universidad, Instituto, Delegación de Hacienda, almacén, etc." ${ }^{2}$. Finalmente también han de considerarse receptores no intencionales todos aquellos que han contemplado la inscripción como visitantes del museo instalado en las dependencias del colegio desde 1933.

\subsection{Elementos objetivos.}

La segunda pregunta que debemos plantearnos al estudiar cualquier inscripción es qué nos quiere transmitir. Se trata, por tanto, de analizar los llamados elementos objetivos: el referente real, el referente mental y el producto apresentador.

Como decíamos anteriormente, el referente real remite al acontecimiento, el objeto o la idea que desea darse a conocer. En el caso de la inscripción ordenada por fray Alonso de Burgos ese referente real lo constituye la edificación de la capilla que tuvo lugar entre 1487 y 1490 . Conocemos a grandes rasgos el proceso de construcción de la capilla. Como relata el Becerro, "el año de 1487 el prior y religiosos del combento de San Pablo, agradecidos a las muchas onrras y favores que havían recivido del illustrísimo señor don fray Alonso de Burgos, obispo de Palencia, y de Valladolid, y la gran suma de dinero que su illustrísima havía gastado en hazer el claustro y sobreclaustro, la librería, el refectorio, los dos salones, alto y vajo, y la maior parte de la portada de la yglesia y la reja de la capilla maior, en cuias obras están gravadas sus armas por donde lo demuestran; hicieron donación

40 J. AGAPITO REVILLA, "La Capilla Mayor de la parroquia de Santiago", Boletín de la Sociedad Castellana de Excursiones, 131 (1913), pp. 241-249.

${ }^{41}$ J. SÁNCHEZ FERNÁNDEZ, Valladolid durante la Guerra de la Independencia Española (1808-1814), Valladolid, 2009.

${ }^{42}$ C. CANDEIRA PÉREZ, Guía del Museo Nacional de Escultura de Valladolid, Valladolid, 1945, p. 11. 
inter vibos a su illustrísima de una capilla que llamavan de el Cruzifixo para que en ella edificase su señoría illustrísima una capilla para su enterramiento (que es la que oy tiene el Collegio) y para su erección y fundación le donó también todo el sitio que ocupa dicho collegio, haviendo obtenido para ello lizencia del M. R. P. Fr. Alfonso de Paredes, vicario general de esta provincia, cuias donaciones pasaron por testimonio de Juan Álbarez de Valladolid en el año sobredicho escritas en pergamino a el número $1^{\circ}$ de este cajón" ${ }^{\prime 4}$. La construcción debió realizarse velozmente, pues, según vimos, en diciembre de 1488 se denunciaba que "la obra que fizieron en la dicha capilla es mala e falsa e non tal qual deba ser porque dis que la dicha obra, por no ser tal, a fecho asiento e aberturas por muchas partes, que junto a esto, la dicha capilla tiene tales defectos que está en peligro" ${ }^{\text {" }}$. Desconocemos cómo repararon los defectos, pero pasado poco más de un año se daba por terminada la construcción de la capilla: "acabose en principio del anno de IUCCCCXC annos".

La inscripción nos recuerda asimismo que la labor del obispo no se limitó a la construcción de la capilla: "en uno con todas las otras obras dell monesterio de que en los letreros dellas se faze mención". Probablemente en este caso no se refiera a la construcción del colegio de San Gregorio, todavía inacabado, sino más bien a todo lo que costeó en el vecino convento de San Pablo, algo que ya nos señalaba el Becerro y que recogía una inscripción elaborada en letra francesa que, según Antolínez de Burgos, recorría el claustro bajo ${ }^{45}$.

Si bien la construcción de la capilla y de las otras obras que menciona constituyen el referente real, la inscripción deja traslucir una serie de elementos que forman parte de eso que Martín Algarra denomina "referente mental". En este sentido queremos llamar la atención sobre tres aspectos que configuraban el mapa conceptual de quienes intervinieron en la elaboración de la inscripción.

En primer lugar, destacamos el carácter netamente gótico tanto de la obra realizada como de la inscripción. Se trata, claro está, de un goticismo tardío, en el que se mezcla la tradición flamenca con el mundo mudéjar castellano. Resulta aún

\footnotetext{
${ }^{43}$ AHN, Códices, libro 1260, f. 263. La Historia del Colegio de San Gregorio incluye la licencia concedida en 1486 por el vicario general, donde se dice: "e para edificar y construir dicho Colegio era necesario que se diese al dicho señor obispo una capilla que es en el dicho monasterio, que se llama el Crucifixo, la cual asimismo quiere magnificar y reedificar y facerla una de las más notables capillas que haya en este reino, donde quiere e acuerda su señoría de elegir sepultura e enterramiento" (M. HOYOS, Historia del Colegio..., vol. I, p. 83).

${ }_{44}^{4}$ AGS, RGS, diciembre de 1488, doc. 131.

45 J. ANTOLÍNEZ DE BURGOS, Historia de Valladolid (1887), Valladolid, 1987, pp. 276277. Quizás en su juventud contemplara la inscripción, pues como él mismo nos dice "se deshizo cuando entró de patrono de este convento el duque de Lerma” (p. 276).
} 
más interesante porque en los mismos momentos el cardenal Pedro González de Mendoza está construyendo también en Valladolid otro colegio, el de Santa Cruz. A través de la influencia de otros miembros de su familia y de su relación con Rodrigo Borja (el futuro Alejandro VI), quería que su obra se ejecutase "al modo romano". De hecho, en la crónica de Pedro Salazar y Mendoza leemos que "poco antes que se acabasse, vino el Cardenal a Valladolid, y pareciéndole que el sobreestante havía andado corto y miserable en el edificio, se lo riñó mucho. Estuvo determinado de hechallo todo por el suelo, y de hazelle de nuevo, conforme a la idea que tenía formada en su ánimo generoso, con quien no se ajustava lo que hasta entonces vio levantado. Assi lo quiso executar si no se lo estorvaran los Reyes, alabándole mucho la obra, y diziendo de ella muchos bienes, y excelencias" "46. Así, podemos establecer una comparación entre el cardenal Mendoza, que utilizó "un nuevo lenguaje, en este caso el italiano, como forma de diferenciación frente a las formas arquitectónicas implantadas" 47 , y fray Alonso de Burgos, que se mantuvo fiel a la tradición gótica que, a juicio de Camón Aznar, tan bien se evidencia en el reinado de Fernando e Isabel ${ }^{48}$. Se trata de una pugna que encuentra su reflejo incluso en la escritura; frente al prolijo epígrafe en letra gótica formada que corona la capilla de San Gregorio, nos encontramos en Santa Cruz con una pequeña placa que ya en capitales humanísticas condensa la información fundamental, el hacedor y la fecha: "PETRUS DE ME/NDOCA CARDI/NALIS HISPAN/IE MCCCCXCI".

La adhesión a los principios de la tradición gótica en esos momentos iba acompañada de la defensa de la monarquía que los encarnaba. Esa glorificación de la monarquía es especialmente patente en la fachada del colegio, cuyo cuerpo superior ha sido interpretado en ocasiones como una representación alegórica de la conquista de Granada o como una alusión a la sabiduría divina que se pretendía impartir en el colegio ${ }^{49}$. Independientemente del sentido de la iconografía, la pre-

46 P. de SALAZAR MENDOZA, Crónica del gran Cardenal de España, don Pedro Gonçález de Mendoça, Toledo, 1625, p. 266.

${ }^{47}$ V. NIETO ALCAIDE et alii, Arquitectura del renacimiento en España (1488-1599), Madrid, 1990, p. 29.

${ }^{48}$ En su conocido artículo "La tradición como originalidad" ( $A B C, 24$ de julio de 1960, p. 3), el catedrático zaragozano sostiene que "la grandeza del reinado de los Reyes Católicos se debe no a su inserción en el mundo renacentista, ya pleno en esa época, sino al revés, a que en él culminan y llegan a su perfección los ideales medievales. Esta continuidad de los programas góticos, que con tanta claridad aparece en su actuación política, se evidencia también en la esfera de las artes".

${ }^{49}$ Para las interpretaciones de la iconografía de la fachada del colegio de San Gregorio, cf. C. J. ARA GIL, Escultura gótica de Valladolid y su provincia, Valladolid, 1977, pp. 240-249, quien declara que "ninguna de estas hipótesis agota sin embargo las posibilidades de interpretación de su significado" (p. 149). 


\section{Francisco J. MOLINA DE LA TORRE \\ LOS ESTUDIOS EPIGRÁFICOS DESDE LA TEORÍA DE LA COMUNICACIÓN}

sencia del escudo de los Reyes Católicos, acompañado de sus emblemas (el yugo y las flechas) y de numerosos "reyes de armas", vincula íntimamente la obra costeada por fray Alonso de Burgos con los monarcas castellanos. La defensa de la monarquía por parte del obispo palentino queda reflejada igualmente en la inscripción de la capilla, donde podemos leer que encargó a capellanes y colegiales que "ruegen a Dios por las vidas e prosperidad de los muy altos e mui gloriosos principes sennores nuestros, el rrey don Fernando e la rreyna donna Ysabel, cuya fechura e crianca e capellan mayor e confesor él es, e por sus animas e por la suya". Se vincula así la monarquía con la acción de Dios; ciertamente no encontramos aquí formulada expresamente la idea de que los reyes llevan a cabo la obra de $\operatorname{Dios}^{50}$, pero sí se subraya la conexión existente entre la divinidad, de quien viene todo poder, y la realeza, que hasta cierto punto comparte atributos propios de aquella: "muy altos e mui gloriosos",

Con ello llegamos al tercer aspecto que pretendemos tratar en cuanto al referente mental: el culto a la cruz. La veneración a la cruz ha de contemplarse en conexión con la más compleja devoción a la pasión que, comenzando en la plena Edad Media, se extiende enormemente durante el bajo medioevo y culmina en la piedad tridentina. Como nos recuerda Torres Jiménez, "la Pasión se convirtió en el motivo central de la devoción, de las representaciones artísticas y de la liturgia" $^{\text {52 }}$. Como ya hemos visto, paralelamente a la construcción de la capilla de fray Alonso de Burgos, se estaba realizando en Valladolid otra obra dedicada a la Santa Cruz, el colegio del cardenal Mendoza. En este caso, no obstante, hay que tener en cuenta que el 6 de julio de 1478 Pedro González de Mendoza había pasado de ser cardenal diácono en la iglesia titular de Santa Maria in Dominica a ser cardenal presbítero en la iglesia de la Santa $\mathrm{Cruz}^{53}$.

\footnotetext{
${ }^{50}$ Esa idea providencialista es común en la época. Por ejemplo, D. de VALERA, Crónica de los Reyes Católicos, ed. J. Mata, Madrid, 1927, p. 6, nos dice: "E como el clementísimo Redemptor nuestro oyese las continuas peticiones e anxiosos gemidos de los pobres e presos por los más poderosos, después de tanta tiniebla, quiso tan claro sol enbiarnos dándonos miraglosamente estos gloriosos sanctos prínçipes rey e reyna don Fernando e doña Isabel, nuestro señores, para los reformar, conservar e acreçentar, e para punir e castigar los sobervios, e destruir e desolar todos los enemigos de nuestra sansta fee católica".

${ }^{51}$ Aunque probablemente no haya influjo directo, era conocida una oración de san Francisco de Asís al crucifijo de San Damiano que comenzaba con las palabras "altissimo glorioso Dio".

${ }^{52}$ R. TORRES JIMÉNEZ, "Notas para una reflexión sobre el cristocentrismo y la devoción medieval a la Pasión y para su estudio en el medio rural castellano", Hispania Sacra, 118 (2006), p. 465 .

${ }^{53}$ Así, la citada crónica del cardenal nos refiere que durante unas reparaciones que encargó en la iglesia de la Santa Cruz de Roma se produjo el hallazgo del verdadero título de la cruz de Cristo, es decir, el madero en el que se inscribió en tres lenguas la frase Jesús de Nazaret, rey de
} 


\section{FRANCISCO J. MOLINA DE LA TORRE \\ LOS ESTUDIOS EPIGRÁFICOS DESDE LA TEORÍA DE LA COMUNICACIÓN}

Cuando en 1487 el obispo palentino recibe la capilla, ya es conocida como del Crucifijo, y, según el Becerro de San Pablo, era propiedad de la familia Torquemada $^{54}$. Al parecer va a conservar la misma advocación, pues el inicio de la inscripción nos recuerda que la capilla fue construida "a servicio e rreverencia del crucifixo presente, ymagen del verdadero crccifixo (sic), nuestro redemptro (sic) Ihesu Christo". No obstante, en la obra de Gonzalo de Arriaga se nos dice que "para la imagen del Santo Crucifijo labró el obispo, frontero de su capilla, otra pequeña y bien curiosa en la que colocó y se ven sus armas", la cual fue posteriormente cedida a la familia Duero ${ }^{55}$. No obstante, sabemos que el retablo de la capilla del obispo contaba con una talla del crucifijo (el crucifixo presente que menciona la inscripción), pues, tras describir el retablo, Gonzalo de Arriaga sigue diciendo: "La devoción principal de la capilla se dirige al Santo Cristo que, crucificado de talla entera, resplandece en medio del suntuoso retablo",56. Además, cuando en 1495 Alejandro VI concede una bula por la que quien en determinadas ocasiones devotamente visitare y rezare en esa capilla alcanzaría diez años y diez cuarentenas de perdón, dice que está "dedicada a honra y bajo la advocación de nuestro Salvador crucificado" ${ }^{, 57}$.

La reverencia a la cruz es también patente en las invocaciones que aparecen al final del epígrafe: "Michi aut[em] absiit (sic) gloriari nisi in cruce Domini nostri Ihesu Christi per quam michi mundus crucifixus est et ego mundo. Michi vivere Christus est et mori lucrum. Gloriari me oportet in cruce domini nostri Ihesu Christi" ${ }^{58}$. Las dos primeras corresponden a citas tomadas de las cartas de san Pablo (Gal 6, 14; Flp 1, 21). Por su parte, el tercer fragmento de la cita estaba to-

los judios. Al respecto, cf. P. de SALAZAR MENDOZA, Crónica del gran Cardenal..., pp. 257258.

${ }^{54}$ AHN, Códices, libro 1261, f. 17.

${ }^{55}$ En M. HOYOS, Historia del Colegio..., vol. I, p. 84, se habla de los Duesos, pero se trata de los Duero, según queda documentado en el Becerro del convento de San Pablo (ff. 74-75) y anteriormente nos narra J. ANTOLÍNEZ DE BURGOS, Historia de Valladolid, p. 280.

${ }^{56}$ M. HOYOS, Historia del Colegio..., vol. I, p. 93. Para las vicisitudes por las que ha pasado la talla, cf. J. URREA FERNÁNDEZ, "El crucifijo del retablo de la capilla de San Gregorio de Valladolid reencontrado", en Actas del Congreso Internacional sobre Gil Siloé y la escultura de su época, Burgos, 2001, pp. 411-417.

${ }^{57}$ El texto latino de la bula aparece en M. HOYOS, Historia del Colegio..., vol. I, pp. 93-94.

${ }^{58}$ La traducción al castellano sería: "Pero lejos esté de mí gloriarme, a no ser en la cruz de nuestro Señor Jesucristo, por quien el mundo ha sido crucificado para mí y yo para el mundo. Para mí vivir es Cristo y la muerte una ganancia. Debo gloriarme en la cruz de nuestro Señor Jesucristo". 
mado de una antífona que se recitaba en algunos rezos de la fiesta de la Conversión de San Pablo ${ }^{59}$.

El tercer elemento objetivo - e indudablemente fundamento de la epigrafía - lo constituye el producto apresentador. Martín Algarra lo define como "el objeto que el actor produce para significar lo que desea expresar, lo que ha conocido como fruto de su percepción o de su reflexión" ${ }^{\prime 60}$. Merced a lo que la fenomenología denomina "apresentación" (el hecho de que una realidad remita a algo que está más allá de ella misma), podemos captar el sentido de una inscripción cuyos referentes tanto real como mental han desaparecido tiempo atrás. Como producto, toda inscripción requiere cierta elaboración, de modo que ha de ser estudiada no sólo en cuanto texto sino también en su materialidad ${ }^{61}$. El estudio de la inscripción, por lo tanto, ha de tener en cuenta los llamados aspectos externos, así como los internos. En cuanto a los primeros, habría que incluir "todos los elementos que integran la materialidad sensible de las inscripciones - soporte, reglado, escritura_ " externos, examinando el soporte, haciendo algunas consideraciones sobre la materialidad del texto y finalmente analizando la inscripción desde el punto de vista paleográfico.

En muchos casos el estudio del soporte se limita a la identificación del material de confección y de sus medidas. Sería de interés que dicho análisis se ocupara también de cuestiones como el tipo de soporte o la ornamentación que lo acompaña. En cuanto al material, el epígrafe fue realizado sobre piedra caliza probablemente traída de canteras situadas en San Miguel del Arroyo y Fuensalda$\tilde{n} a^{63}$. Respecto a la tipología, el soporte podría ser clasificado como un friso ${ }^{64}$,

\footnotetext{
${ }^{59}$ Dicha festividad, celebrada el 25 de enero, era una de las ocasiones que mencionaba la bula de Alejandro VI.

${ }^{60}$ M. MARTÍN ALGARRA, Teoría de la comunicación..., p. 131.

${ }^{61}$ El decidido planteamiento de Navascués mantiene plena actualidad: "La inscripción es, pues, como todo escrito, un cuerpo físico en el cual se funden en un solo ser la escritura y su soporte, el cual es a su vez, la expresión plástica de un lenguaje y de un pensamiento" (J. M. de NAVASCUÉS y de JUAN, El concepto de la epigrafía..., pp. 65-66).

${ }^{62}$ V. GARCÍA LOBO - M. E. MARTÍN LÓPEZ, De epigrafía medieval..., p. 14.

${ }^{63}$ En una escritura de concierto fechada el 16 de febrero de 1524, fray Cristóbal de Toro, rector del Colegio, encarga la construcción de una azotea a los maestros Gaspar de Solorzano y Lorenzo de Leán, y dice: "el entablamento ha de ser de la piedra de Sant Miguel del Arroyo" y más adelante "se haga de sillería de piedra de Fuensaldaña que ha de ser de esta cantera toda la sillería que haya menester toda la obra". Además, se indica que "para hazer y cumplir toda esta dicha obra podamos tomar la piedra de San Miguel del Arroyo que agora está en el corral del colegio por asentar y aprovecharnos della para la dicha obra", por lo cual hemos de suponer que la piedra almacenada había llegado allí con motivo de la construcción del colegio bajo las indicaciones de
} 
aunque en este caso la inscripción va grabada directamente sobre los sillares del muro. La inscripción, como veremos se dispone casi siempre en dos líneas, delimitadas en la parte superior, intermedia e inferior por molduras decoradas. La banda superior y la intermedia presentan una ornamentación que consta de dos toros y una escocia, mientras que la moldura inferior consiste en un motivo sogueado pintado en verde y blanco, en relación con los colores del escudo del prelado $^{65}$. Este es usado profusamente en la ornamentación de la inscripción, pues tanto en las esquinas como en las pilastras que sustentan los nervios de la bóveda se interrumpe el texto de la banda inferior y se emplea dicho espacio para la colocación de uno o dos ángeles que sostienen el escudo del obispo ${ }^{66}$.

Pasamos a continuación a centrarnos en el texto en sí, ocupándonos en primer lugar de algunos aspectos materiales. Hay numerosos factores que condicionan la ejecución del texto que va a figurar en un epígrafe ${ }^{67}$. El texto está dispuesto horizontalmente ${ }^{68}$ en dos líneas de texto superpuestas que recorren los muros de la capilla, a excepción de la pared norte en la que encontramos una única línea. Ello se debe, casi con toda seguridad, a que la parte inferior quedaba oculta tras el retablo que mandó construir el obispo para adorno de la capilla a los maestros Diego de la Cruz y Gilles [Gil de Siloé] ${ }^{69}$. La lectura del texto comienza en la pilastra que separa el ábside del muro este. En su época, cuando se accedía a la capilla desde el crucero de la iglesia de San Pablo, el espectador encontraba el texto dispuesto de tal forma que comenzaba su lectura de forma natural de izquierda a derecha en el muro que se hallaba frente a él. En cuanto a la técnica de ejecución, de la cual más adelante hablaremos detenidamente, la inscripción fue incisa y pintada en oro.

Alonso de Burgos. Vid. E. GARCÍA CHICO, Valladolid. Papeletas de historia y arte, Valladolid, 1958, pp. 9-11. $\mathrm{XV}$.

${ }^{64}$ Las inscripciones elaboradas en un friso van a desarrollarse en Castilla a lo largo del siglo

${ }^{65}$ Gonzalo de Arriaga refiere el origen del blasón episcopal de Alonso de Burgos: "Aficionóse tanto a su dueño que, cuando los Reyes Católicos le hicieron obispo, tomó por armas las propias del obispo don Pablo, flor de lis blanca en campo verde, añadiendo por orla las de la religión, cuatro cruces dominicanas o de inquisición en campo blanco" (M. HOYOS, Historia del Colegio..., vol. I, p. 17).

${ }^{66}$ F. WATTEMBERG SAMPERE, Museo Nacional de Escultura de Valladolid, $2^{\mathrm{a}}$ ed., Madrid, 1972, p. 31, vincula estas imágenes de ángeles a Sebastián de Almonacid, escultor que trabaja en el círculo de Juan Guas.

${ }^{67}$ Para los condicionantes de la escritura, cf. I. di STEFANO MANZELLA, Mestiere di epigrafista. Guida alla schedatura del materiale epigrafico lapideo, Roma, 1987, p. 137.

${ }^{68}$ A juicio de I. di STEFANO MANZELLA, Mestiere di epigrafista..., p. 131, la disposición horizontal constituye "el sistema más idóneo para la escritura y para la lectura".

${ }^{69}$ AHN, Códices, libro 1260, ff. 263-264. 
A nivel paleográfico, el epígrafe está realizado en escritura gótica minúscula formada, la cual se impone en la provincia de Valladolid desde el segundo tercio del siglo XV y perdura hasta el siglo XVI. Presenta algunos de los rasgos característicos de dicha escritura, como el carácter anguloso de los trazos, el contraste entre finos y gruesos o la unión de curvas contrapuestas. No obstante, este último rasgo no se da de forma constante (del, dotó) y además no aparece ningún ejemplo de $r$ redonda (por, señores). Por lo general, la letra está formada por trazos verticales rematados en bisel que ocupan toda la línea del renglón y a los que, bien en su parte superior (como en el caso de la $i$ ), bien en la inferior (por ejemplo, en la $l$ - cuyo remate superior es bífido-), o bien en ambas (tal como sucede, entre otras, con las letras $e, n, r)$, se les añade un pequeño trazo oblicuo. Destacaremos algunas peculiaridades que encontramos en el trazado de las letras. En el caso de la $r$ y de la $e$, el pequeño trazo oblicuo de la parte superior está rematado por otro curvilíneo muy fino que cae hacia abajo. La $s$ de doble curva se emplea a final de palabra, aunque también encontramos al final de palabra (las, ánimas). La $s$ de doble curva consta de seis trazos, si bien para la incisión en piedra se requerirían al menos ocho. De un modo similar se traza la $z$, si bien la diferencia entre ambas parece radicar en que la $z$ carece de la fina línea ornamental que parte del trazo oblicuo superior. Por su parte, la $y$ consta de dos trazos verticales semejantes a una $i$ (aunque en algunos casos no llegan hasta la parte inferior del renglón) y de un tercer trazo curvilíneo que parte del extremo inferior del trazo vertical de la derecha, roza el de la izquierda y vuelve hacia la derecha, terminando con un engrosamiento en forma de rombo. Junto a la gótica minúscula, encontramos tres ejemplos de gótica mayúscula. Al comienzo de la inscripción aparece una $A$ gótica mayúscula ornamentada en el vértice superior, el travesaño y los extremos inferiores mediante trazos curvos más finos. En el inicio de la segunda línea de texto encontramos una $E$ de tipo uncial con un trazo vertical que la cierra. También se emplea la $R$ mayúscula con valor de /rr/ en diversas ocasiones (rreverencia, rreverendo, rrey, rreyna).

Al margen de aquellas ocasiones en que se produce la unión de curvas contrapuestas (del, don, Pernía, etc.), son escasos los nexos que se emplean, limitándose a la conocida unión de $s$ alta y $t$ (esta, monesterio). Mucho más abundantes son las abreviaturas, utilizándose una variada gama de signos abreviativos. El más común es la línea superpuesta, la cual adopta formas diversas, más o menos curvas, convirtiéndose en alguna ocasión en un simple punto superpuesto (obispo, qual, nostri). Con este signo encontramos abreviadas sobre todo nasales (con, mención, celebren, digan, ruegen, confesor, capellán, comencose), pero también 
sirve como signo abreviativo general (que, nuestro, Fernando). Por otro lado, el texto a veces emplea una o varias letras superpuestas (prosperidad, rreverendo, magnífico). Además, se utiliza la $p$ partida con valor tanto de per (prosperidad) como de par (para) y la $v$ partida con valor de ver (verdadero). El ordinator también recurre a los llamados nomina sacra para las referencias a Jesucristo en distintos casos (ihu, xpo, xpi). Por último, hay ocasiones donde la abreviatura no presenta ningún elemento identificador (que, autem).

Asimismo, el epígrafe incluye algunos signos de interpunción consistentes en dos o tres puntos de aspecto romboidal unidos por un fino trazo curvilíneo. En algunos casos, su uso responde a la proximidad de la pilastra (crucifixo:presente; donna:ysabel); en otras ocasiones la intención es separar ideas, como ocurre con los tres puntos que separan la invocación inicial del verbo principal (Ihesu Christo:fizo esta capilla), los dos puntos que aparecen al final de la intitulación (de Pernía:en uno con) o los signos que coloca antes y después de la mención de la capilla como lugar de su sepultura (dotó:eligió para su sepoltura:para que).

Tradicionalmente se ha prestado mucha más atención a los aspectos internos de la inscripción, considerando que ellos son los que proporcionan el material necesario para la labor filológica o histórica. Conscientes de la importancia de los elementos estudiados anteriormente, no podemos olvidar, sin embargo, estos aspectos en los que generalmente se han centrado los estudios de los investigadores. Tres elementos analizaremos en este apartado: la lengua, la tipología textual y la datación.

En lo concerniente a la lengua, el texto está escrito en su mayor parte en castellano, aunque concluye con una serie de invocaciones en latín. Se trata de citas bíblicas, muy probablemente tomadas, como dijimos más arriba, no directamente de la Escritura, sino de los libros litúrgicos empleados en la oración de la comunidad. Apenas presenta errores, al margen de la palabra absit, que, tal vez por el desconocimiento del latín por parte del ordinator, encontramos como absiit, con un punto superpuesto entre las dos íes. Por otro lado, la única peculiaridad que encontramos - frecuente, no obstante, en la Edad Media - es la forma michi por mihi. Respecto al castellano, simplemente indicaremos que sigue presente la inestabilidad de timbre en la vocal inacentuada (sepoltura). Además, se produce la pérdida de la $h$ inicial (oras), la oscilación entre y e $i$ (ymagen, Ysabel, muy, mui) y el uso de la grafía $c$ y no $c ̧$ para la africada sorda (servicio, rreverencia, Palencia, mención, crianca, comencose).

La tipología textual de los epígrafes medievales se ha desarrollado sobre todo a partir de los estudios diplomáticos de Canellas López, reelaborados por Gar- 


\section{FRANCISCO J. MOLINA DE LA TORRE \\ LOS ESTUDIOS EPIGRÁFICOS DESDE LA TEORÍA DE LA COMUNICACIÓN}

cía Lobo para aplicarlos al mundo de las inscripciones ${ }^{70}$. En cualquier caso, el letrero de la capilla de San Gregorio no puede reducirse a una de las categorías enumeradas en esos estudios. En general correspondería a un monumentum aedificationis en el que aparece una roboratio, aunque también encontramos invocationes al principio y al final, además de lo que podríamos calificar como mandatum cuando refiere lo que deben hacer colegiales y capellanes. Dada esta mezcolanza tipológica, para analizar la inscripción desde una perspectiva diplomática, convendría dividir la inscripción:

Invocatio inicial: "A servicio e rreverencia del crucifixo presente, ymagen del verdadero crucifixo nuestro redemptor Ihesu Christo".

Dispositio: "Fizo esta capilla [...] en uno con todas las otras obras dell monesterio de que en los letreros dellas se faze mención, la qual dotó, eligió para su sepoltura, para que los colegiales deste colegio e capellanes de su capilla celebren las misas e digan las oras canónicas e ruegen a Dios por las vidas e prosperidad de los muy altos e mui gloriosos principes sennores nuestros el rrey don Fernando e la rreyna donna Ysabel, cuya fechura e crianca e capellan mayor e confesor él es, e por sus animas e por la suya".

Intitulatio: "El muy rreverendo e muy magnifico sennor, el sennor don Alfonso de Burgos, obispo de Palencia, conde de Pernía".

Datatio: "E comencose esta capilla en fin del anno de IUICCCCLXXVII annos; acabose en principio del anno de IUCCCCXC annos".

Invocatio final: "Michi autem absiit (sic) gloriari nisi in cruce Domini nostri Ihesu Christi per quam michi mundus crucifixus est et ego mundo; michi vivere Christus est et mori lucrum; gloriari me oportet in cruce domini nostri Ihesu Christi”.

Por último, dentro de los elementos internos de la inscripción hemos de considerar la fecha. Pese a que no hace referencia explícita, el texto seguramente está datado de acuerdo con el sistema de la Navidad, el que entonces se emplea comúnmente. El epígrafe nos proporciona la fecha de inicio ("comencose esta capilla en fin del anno de IUICCCCLXXVII annos") y fin de la construcción ("acabose

${ }^{70}$ Á. CANELLAS LÓPEZ, Diplomática hispano-visigoda, Zaragoza, 1979, pp. 76-77, habla de "actas de notoriedad", distinguiendo cuatro tipos (epitaphia, consecrationes, monumenta aedificationis y notitiae proprietatis). A partir de esa clasificación primera, se han ido estableciendo nuevas categorías, siendo una de las últimas propuestas M. E. MARTÍN LÓPEZ - V. GARCÍA LOBO, "La Epigrafía medieval en España. Por una tipología de las inscripciones", en VIII Jornadas Cientificas sobre Documentación de la Hispania altomedieval (siglos VI-X), Madrid, 2009, pp. 185-214. 
en principio del anno de IUCCCCXC annos"), datos malinterpretados desde el siglo XVIII, dando origen, como veremos, a distintas propuestas de explicación.

\subsection{Elementos práxicos.}

Junto a los elementos subjetivos y los objetivos, Martín Algarra contempla una tercera clase: los práxicos. Se trata de las acciones desarrolladas por quien o quienes desean transmitir un mensaje y por quien o quienes desean desentrañar su contenido. Resume en dos dichas operaciones: "Llamaremos a esas acciones expresión e interpretación, respectivamente" ${ }^{71}$.

Primeramente, la expresión. Se trata de aquella acción significativa que tiene por objeto manifestar lo que se piensa o siente. Desde el punto de vista de la epigrafía, la expresión engloba toda la elaboración de la inscripción, partiendo de su concepción primera y llegando a su colocación en el lugar dispuesto por el promotor.

El primer paso es la formulación del deseo de que se elabore una cierta inscripción. Dependiendo de la formación de quien la encargaba, el texto podía facilitarlo él mismo o recurrir a un letrado para que lo compusiera ${ }^{72}$. En nuestro caso, es probable que fuera fray Alonso quien proporcionara el contenido del epígrafe. La inscripción, aunque hoy en día presenta algunas alteraciones, diría lo siguiente:

A servicio e rreverencia del crucifixo presente, ymagen del verdadero crucifixo nuestro redemptor Ihesu Christo fizo esta capilla el muy rreverendo e muy magnifico sennor, el sennor don Alfonso de Burgos, obispo de Palencia, conde de Pernía, en uno con todas las otras obras dell monesterio de que en los letreros dellas se faze mención, la qual dotó, eligió para su sepoltura, para que los colegiales deste colegio e capellanes de su capilla celebren las misas e digan las oras canónicas e ruegen a Dios por las vidas e prosperidad de los muy altos e mui gloriosos principes sennores nuestros el rrey don Fernando e la rreyna donna Ysabel, cuya fechura e crianca e capellan mayor e confesor él es, e por sus animas e por la suya. E comencose esta capilla en fin del anno de IUICCCCLXXVII annos; acabose en principio del anno de IUCCCCXC annos. Michi autem absit gloriari nisi in cruce Domini nostri Ihesu Christi per quem michi mundus crucifixus est et ego mundo; michi vivere Christus est et mori lucrum; gloriari me oportet in cruce domini nostri Ihesu Christi.

\footnotetext{
${ }^{71}$ M. MARTÍN ALGARRA, Teoría de la comunicación..., p. 133.

${ }^{72}$ R. FAVREAU, Épigraphie médiévale, pp. 138-140.
} 
Una vez redactado el texto, dado que en nuestro epígrafe no se perciben los pasos intermedios que mencionamos anteriormente, se procedería a su plasmación en el soporte. Lo primero que se llevaría a cabo, tal como se denomina a partir de los estudios de Mallon, es la ordinatio, a la que considera "la fase de la composición epigráfica" y de la que dice que "tiene un gran interés para la paleografía" Consiste en traducir en letras monumentales sobre la piedra la redacción que se le había remitido, empleando un pedazo de tiza, un trozo de carbón, una punta seca o un pincel. García Lobo y Martín López distinguen varios momentos en esta fase ${ }^{74}$. La "impaginación", tomando una expresión propia de la codicología, consistiría en la estructuración del texto en el campo epigráfico considerando las características de este ${ }^{75}$. En este momento habría de considerarse el pautado, el tamaño de las letras, el número de renglones, las posibles abreviaturas, los nexos, etc. En la inscripción se percibe una pequeña línea, al parecer realizada con una punta seca, que marca el límite superior de la letra. La preparación del espejo epigráfico, que supondría el pulimiento del soporte que va a acoger la inscripción, no parece haber dejado huellas en el epígrafe que estamos estudiando. Finalmente, la transliteración sería la plasmación de la inscripción usando un pedazo de carbón, de tiza, un punzón... La observación detallada del epígrafe de la capilla no ha revelado cómo se llevó a cabo dicha tarea, pues los restos de carboncillo o tiza fueron eliminados por el artesano que grabó las letras. No obstante, una de las puertas góticas que aún existen en el claustro del Colegio de San Gregorio (la que hoy en día da acceso a la sala III) presenta una inscripción que no fue incisa en su totalidad y se aprecian varias letras trazadas con carboncillo, siendo probable que en el friso se usase el mismo método. Así, el ordinator habría dispuesto el texto en los muros de la siguiente manera, haciendo uso de abreviaturas, nexos, etc.:

A servicio e Reverencia del crucifixo : presente ymagen del edā̄o crccifixo

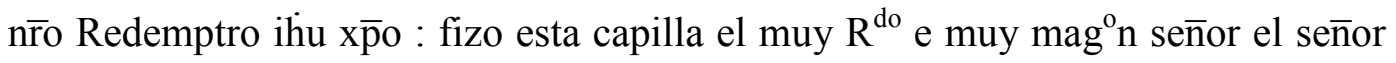

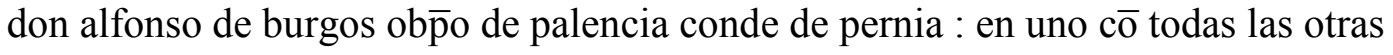
obras dell monesterio de $\mathrm{q}$ en los letreros della se faze mécion la q 1 doto : eligio pa su sepoltura : pa $\overline{\mathrm{q}}$ los colegiales deste colegio e capellanes de su capilla celebrē las misas e diga $\bar{a}$ las oras canonicas e ruegē a dios por las vidas e $\operatorname{pr}^{\mathrm{o}}$ spidad de

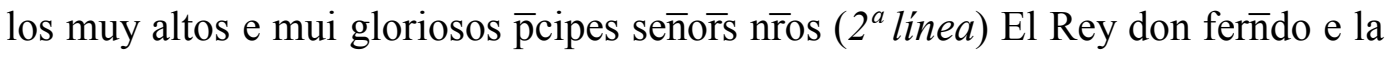
Reyna donā ysabel cuya fechura e crianca e capellā mayor e cōfesor el es e por sus animas e por la suya e comēcose esta capilla en fin del an̄o de

\footnotetext{
${ }^{73}$ J. MALLON, Paléographie romaine, Madrid, 1952, p. 58.

${ }^{74}$ V. GARCÍA LOBO - M. E. MARTÍN LÓPEZ, De epigrafía medieval..., p. 29.

${ }^{75}$ Cf. G. SUSINI, Il lapicida romano, Roma, 1962, p. 64.
} 
IUICCCCLXXXVII an̄os acabose en principio del an̄o de IUCCCCXC ā̄ michi aut absï it głriari nisi in cruce dni nri ihů xp̉ p q⿳亠口冋 michi mundus crucifixus est et ego mundo michi vivere $\mathrm{xp}^{0} \mathrm{~s}$ est et mori lucrum gloriari me oportet in cruce dni nri

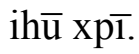

Una vez perfilada la inscripción en la pared, se procede a su fijación definitiva. En ese sentido, se utiliza generalmente el término incisio para referirse a cualquier clase de técnica empleada en la ejecución de un epígrafe, aunque existen múltiples maneras de hacerlo ${ }^{76}$. En nuestro caso nos encontramos con lo que Manzella denomina scrittura a solchi ${ }^{77}$, aquella en la que algún trazo de la letra está representado por un surco (normalmente de sección en v). Se trata de la técnica más extendida debido a la relativa sencillez de ejecución, a la perduración en el tiempo, a la resistencia a los elementos atmosféricos y a la gran legibilidad que presenta. En nuestro caso, el surco de la letra se caracteriza por su anchura y poca profundidad. Además, una vez incisa la letra directamente en los sillares, se pintó en oro, con el objeto de que destacase y su lectura resultase más sencilla.

El último aspecto del planteamiento de Martín Algarra concierne a la interpretación, a su juicio, el segundo de los elementos práxicos. Como dijimos al comienzo, la inscripción, antes de llegar a nosotros, ya ha sido objeto de innumerables interpretaciones, tanto correctas como erróneas, algunas de las cuales han dejado huella importante.

En primer lugar, ya hablamos del mercader Luis de la Serna. Cuando en 1498 se reconstruye a su costa la capilla mayor de la parroquia de Santiago Apóstol, en el contrato se lee que "en el tablamiento a de aver una copada de un palmo y medio en que vengan las letras esculpidas que mandare el dicho Luis de la Serna e an de ser como las de la capilla del señor obispo de Palençia",78. Ello nos permite vislumbrar la favorable acogida del letrero entre quienes primero lo vieron. Probablemente, la petición del mercader no se basa tanto en su claridad y legibilidad cuanto en criterios estéticos. De hecho, los fragmentos del epígrafe de Santiago que se conservan presentan una tendencia aún mayor a lo ornamental (en detrimento de su legibilidad), de tal modo que el trazo vertical de la letra gótica se ve decorado con engrosamientos de sección romboidal huecos en el centro.

Una segunda interpretación que podemos mencionar (tal vez no en sentido cronológico, pues no sabemos cuándo tuvo lugar) son los arreglos que se llevaron

\footnotetext{
${ }^{76}$ Sobre el tema de la técnica, cf. R. FAVREAU, Épigraphie médiévale, pp. 51-52; I. di STEFANO MANZELLA, Mestiere di epigrafista..., pp. 137-145.

${ }^{77}$ I. di STEFANO MANZELLA, Mestiere di epigrafista..., pp. 138-141.

${ }^{78}$ J. AGAPITO REVILLA, "La Capilla Mayor...”, p. 244.
} 
a cabo en la inscripción. No sabemos quién los realizó, pero o bien no interpretó correctamente su sentido o bien se equivocó al reelaborar las letras dañadas. Así, en la segunda ocasión que aparece la palabra "crucifixo" es perceptible que los sillares han sido cubiertos por una capa de yeso, pintándose por encima una letra $c$ de mayor tamaño y ligeramente más inclinada, de tal modo que en la actualidad tenemos "crccifixo". Algo similar pudo haber sucedido con la palabra "rredemptor", tal vez dañada por las humedades procedentes de la ventana superior, donde hoy en día podría leerse "rredemptio", aunque hemos de reconocer que la penúltima letra no parece una $i$, sino una $r$ a la que le falta el trazo superior.

Otras interpretaciones de las que tenemos noticia son los intentos de lectura en el siglo XVIII. Rafael de Floranes, que recorrió las diversas iglesias y conventos de Valladolid anotando los epígrafes que encontró a su paso, nos refiere lo siguiente en su manuscrito sobre las Inscripciones de Valladolid:

Dicen dos letreros bien conservados de letra mui angosta y antigua, grande y alta que corren por la cornisa de la capilla: ":::: servicio e reverencia del crucifixo desta presente ymagen del verdadero ::: Ih $\bar{u}$ Xptō, fiso esta capilla el muy $\mathrm{R}^{\mathrm{do}} \mathrm{e}$ muy magn ${ }^{\text {co }}$ Señor el Señor Don Alfonso de Burgos, ob̄̄o de Palencia conde de Pernía, en uno cō todas las otras obras deste monesterio q en los letreros dellas se fase mēcion: la ql dotó e cogio pa su sepoltura e pa $\bar{q}$ los Colegiales e Capellanes desta capilla se ::::: del Rey Don Fernādo e la Reyna Doña Ysabel :::: cuyo capellán e confesor él es, e por sus ánimas e por las :::: Comēzose esta capilla en fin del año de IUCCCCLXXXIIII años; acabose a principio del año de IUCCCCXC $\bar{a} \mathrm{o}^{\mathrm{s}, 79}$.

Más importante por su repercusión fue la interpretación que hizo fray Domingo Díaz, regente del colegio a comienzos del siglo XIX, en su Relación topográfica antigua y moderna y variaciones del insigne colegio de San Gregorio de Valladolid, del orden de predicadores (1828). Tal como dice Hoyos en su obra, la leyó "a fuerza de mucho tiempo, paciencia y perseverancia". Su versión es la siguiente:

El letrero más alto da vuelta a toda la cornisa de la Capilla y parece que debe empezar en la columna del lado de la epístola. Dice así: "A servicio e reverencia del crucifixo presente, imagen del verdadero crucifixo, Ntro. Redemptor Jesuchristo: fiso esta Capilla el mui Rvdo. e mui magnífico señor el Señor Don Alfonso de Burgos, obispo de Palencia, conde de Pernía... con todas las otras obras del monasterio de que en los letreros dellas se fase mención, la qual dotó e eligió para su sepoltura, e para que los Collegiales de este Collegio e Capellanes de su Capi-

\footnotetext{
${ }^{79}$ Biblioteca Nacional, Ms. 11246, f. 211r.
} 
1la celebren las misas e digan las horas canónicas e rueguen a Dios por las vidas e prosperidad de los mui altos e mui gloriosos Príncipes señores nuestros". Si este letrero se quiere empezar a leer por la palabra fixo, que quiere decir fizo o hizo, lo mismo es y lo mismo dirá. Debajo del letrero alto hay otro dividido en dos trozos, uno latino y otro castellano. El latino empieza sobre la entrada al coro alto, al lado izquierdo, y dice así: "Mihi autem absit gloriari nisi in cruce Domini nostri Jesuchristi, per quem mihi mundus crucifixus est et ego mundo. Mihi vivere Christus est et mori lucrum. Gloriari me oportet in cruce Domini nostri Jesuchristi”. Concluye este trozo junto a la columna del lado de la epístola, y luego sigue el otro trozo castellano en la misma línea: "El (o $A l$, que no se distingue bien) Señor Rey D. Fernando, e la Reyna $\mathrm{D}^{\mathrm{a}}$ Isabel, e una fechura, e crianza, e Capellán mayor, e confesor... (parece que dice elese), por sus ánimas e por la suta comenzóse esta Capilla en fin del año de MCCCCLXXXIIII, acavose en principio del año MCCCCXC años" $"$.

Al margen de los cambios que introduce por motivos ortográficos (imagen, monasterio, Isabel, hora, etc.), hay varias interpretaciones confundidas. En primer lugar, respecto al inicio de la inscripción, tiene razón al decir que "debe empezar en la columna del lado de la epístola", por lo que no resulta válida su lectura si comenzamos a leer por "fizo esta capilla". Ello se debe a que el segundo renglón sigue naturalmente al primero, de modo que en el mismo lugar en que empieza el superior, lo hace el inferior: "por las vidas e prosperidad de los mui altos e mui gloriosos Príncipes señores nuestros / el sennor rrey don Fernando", concluyendo esta segunda línea con las invocaciones en latín. En segundo lugar, en el espacio en blanco que deja tras la intitulación del obispo debemos leer "en uno", uniendo las palabras "fizo esta capilla", que preceden a la mención de fray Alonso, con lo que viene a continuación "en uno con todas las otras obras del monesterio". Además, leyó de forma errónea parte de la segunda línea en castellano, de modo que no dice "e una fechura, e crianza, e Capellán mayor, e confesor... (parece que dice elese), por sus ánimas”, sino "cuya fechura e crianca e capellán mayor e confesor él es, e por sus ánimas". Finalmente, también erró respecto a la fecha de inicio de las obras, pues la inscripción reza "en fin del anno de IUICCCCLXXXVII" y no "MCCCCLXXXXIIII".

En cualquier caso, la lectura de fray Domingo Díaz, reproducida en el segundo apéndice de la Historia del Colegio de San Gregorio de Hoyos, será considerada, por así decirlo, la lectura "canónica" y será utilizada en todos los estudios

\footnotetext{
${ }^{80}$ M. HOYOS, Historia del Colegio..., vol. I, pp. 455-456.
} 
sobre la capilla realizados desde mediados del siglo pasado ${ }^{81}$. El principal problema va a suscitarlo la fecha de inicio de la construcción, lo cual va a llevar al planteamiento de diversas hipótesis para explicar cómo fray Alonso de Burgos, que en 1484 era obispo de Cuenca y todavía no había recibido los terrenos donde se levantó, pudo comenzar la edificación en tan temprana fecha ${ }^{82}$.

\section{A MODO DE CONCLUSIÓN.}

En la actualidad la inmensa mayoría de epigrafistas, tanto del mundo clásico como de época medieval, coinciden en considerar la inscripción como un medio de comunicación al servicio de determinadas personas o comunidades. Por ello, pensamos que sería posible emplear el marco teórico del mundo de la comunicación para desarrollar nuestro trabajo epigráfico. No obstante, dada la multiplicidad de teorías de la comunicación existentes, optamos por aplicar la propuesta de Manuel Martín Algarra, quien distingue tres elementos fundamentales en el proceso comunicativo. A la luz de este planteamiento hemos estudiado la inscripción que remata la capilla del Museo Nacional de Escultura de Valladolid.

De este modo, comenzamos planteándonos quienes están implicados en el proceso de comunicación del que forma parte el epígrafe, desde el promotor de la obra, el obispo fray Alonso de Burgos, quien se sirve de la inscripción no sólo para dar cuenta de lo realizado sino también para promover su persona como alguien del círculo de los reyes Fernando e Isabel, pasando por quienes realmente la llevaron a cabo, ya fueran estos artistas de renombre — como Juan Guas y Juan de Talavera- o artesanos anónimos — como quien dispuso el epígrafe en el muro y quien lo grabó y pintó- , hasta aquellos en quienes pensaba el obispo al componer el epígrafe - los colegiales y capellanes - o quienes lo han contemplado sin ser receptores intencionales — como los soldados franceses allí apostados, los turistas que visitan cada año el museo o los estudiosos que analizan la inscripción buscando información de diverso tipo-.

${ }^{81}$ F. WATTENBERG SAMPERE, Museo Nacional de Escultura..., pp. 29-40; J. J. MARTÍN GONZÁLEZ, El Museo Nacional de Escultura de Valladolid, León, 1977, pp. 14-17; E. GARCÍA DE WATTENBERG, Museo Nacional de Escultura. Valladolid. Guía del visitante, Valladolid, 1978, pp. 60-63; C. J. ARA GIL, Escultura gótica..., pp. 227-231; E. GARCÍA DE WATTENBERG, Museo Nacional de Escultura. Valladolid. Guía del visitante, Valladolid, 1978, pp. 60-63; J. CASTÁN LANASPA, Arquitectura gótica religiosa en Valladolid y su provincia (siglos XIIIXVI), Valladolid, 1998, pp. 144-157. pp. 13-14.

${ }^{82}$ M. A. MARTÍN GONZÁLEZ, La Capilla del Colegio de San Gregorio, Valladolid, 1982, 


\section{Francisco J. MOLINA DE LA TORRE \\ LOS ESTUDIOS EPIGRÁFICOS DESDE LA TEORÍA DE LA COMUNICACIÓN}

En segundo lugar, pasamos revista a los tres elementos objetivos que menciona Martín Algarra. La construcción de la capilla es, sin duda, el referente real, es decir, aquella realidad de la cual da cuenta la inscripción encargada por el obispo palentino. No obstante, nuestro acceso a la realidad no es directo, de modo que todo referente real viene mediado por un referente mental. Así pues, la inscripción refleja no tanto la realidad en sí cuanto el mapa mental de quien ordena su realización. En ese sentido, hemos analizado cómo el epígrafe refleja la adhesión a la tradición gótica, la vinculación con la monarquía isabelina y el culto a la cruz que venía extendiéndose sobre todo desde el siglo XIII. Finalmente, esos referentes real y mental se plasman en un producto apresentador, que nos remite a una realidad más allá de sí mismo. Este producto apresentador es el epígrafe tal como ha llegado a nosotros, y su estudio conlleva el análisis no sólo de los aspectos internos (el texto que nos proporciona cierta información), sino también de los aspectos externos: la inserción del epígrafe en la obra en su conjunto y la materialidad tanto del soporte como del texto. Aquí estudiamos, por un lado, el soporte en sus aspectos materiales, tipológicos, ornamentales, y por otro, la escritura también en cuanto a su disposición, la técnica empleada en la ejecución, el tipo de letra, los recursos caligráficos, etc.

Finalmente, nuestra atención se ha centrado en los elementos práxicos, es decir, aquellas acciones que han de llevar a cabo tanto quienes desean formular el mensaje epigráfico como quienes desean desentrañar su sentido. Por ello, hablamos de expresión, recogiendo en dicho término todo lo que conlleva la elaboración del epígrafe, desde la primera formulación del deseo por parte del comanditario hasta la capa de pintura que se le dio tras el grabado de las letras, y de interpretación, entendiendo esta como toda interacción con el mensaje, ya sea la positiva recepción que le dieron en su época, las fallidas correcciones que se hicieron en el epígrafe o las lecturas y estudios, tanto acertados como erróneos, realizados a lo largo de los siglos.

En definitiva, considerar el epígrafe desde la teoría de la comunicación nos permite contemplar el proceso comunicativo en su integridad, desde la concepción primera por parte de quien encarga la inscripción hasta la más reciente lectura e interpretación por parte de los estudiosos. Creemos, por tanto, que se trata de una posible línea de investigación que contempla la inscripción desde múltiples perspectivas y resulta aplicable a epígrafes de cualquier tiempo y lugar, lo cual permite superar, por un lado, una excesiva fragmentación en el análisis de determinada inscripción (integrando en el estudio aspectos artísticos, paleográficos, filológicos, históricos, etc.) y, por otro, la acentuada división de la epigrafía en clásica, me- 
Francisco J. Molina de la TORRE

LOS ESTUDIOS EPIGRÁFICOS DESDE LA TEORÍA DE LA COMUNICACIÓN

dieval, etc., como si el objeto de estudio no fuera en todos los casos un producto mediante el que determinadas personas o grupos expresan un mensaje que otras personas o grupos deben interpretar.
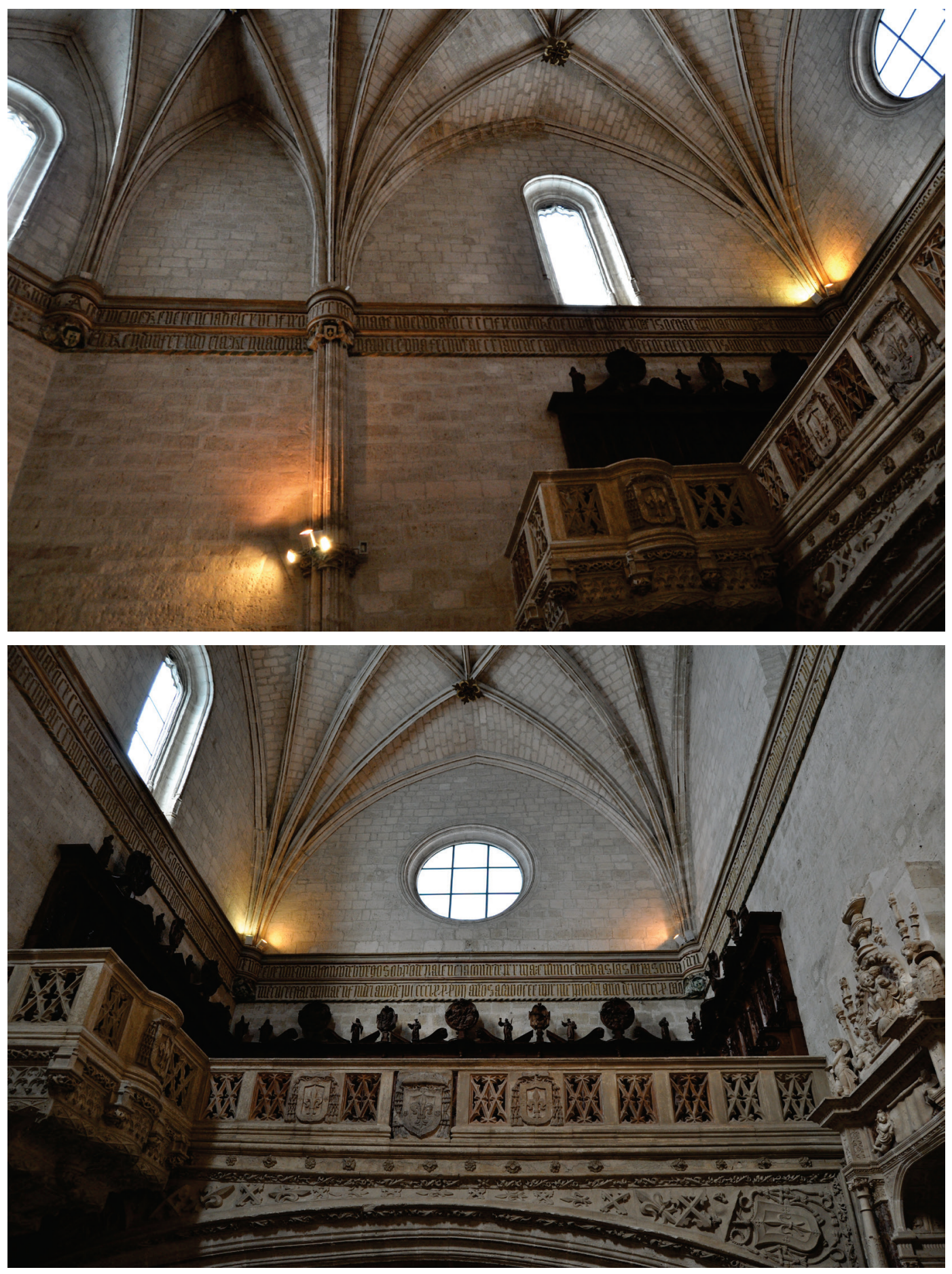
FRANCISCO J. MOLINA DE LA TORRE

LOS ESTUDIOS EPIGRÁFICOS DESDE LA TEORÍA DE LA COMUNICACIÓN
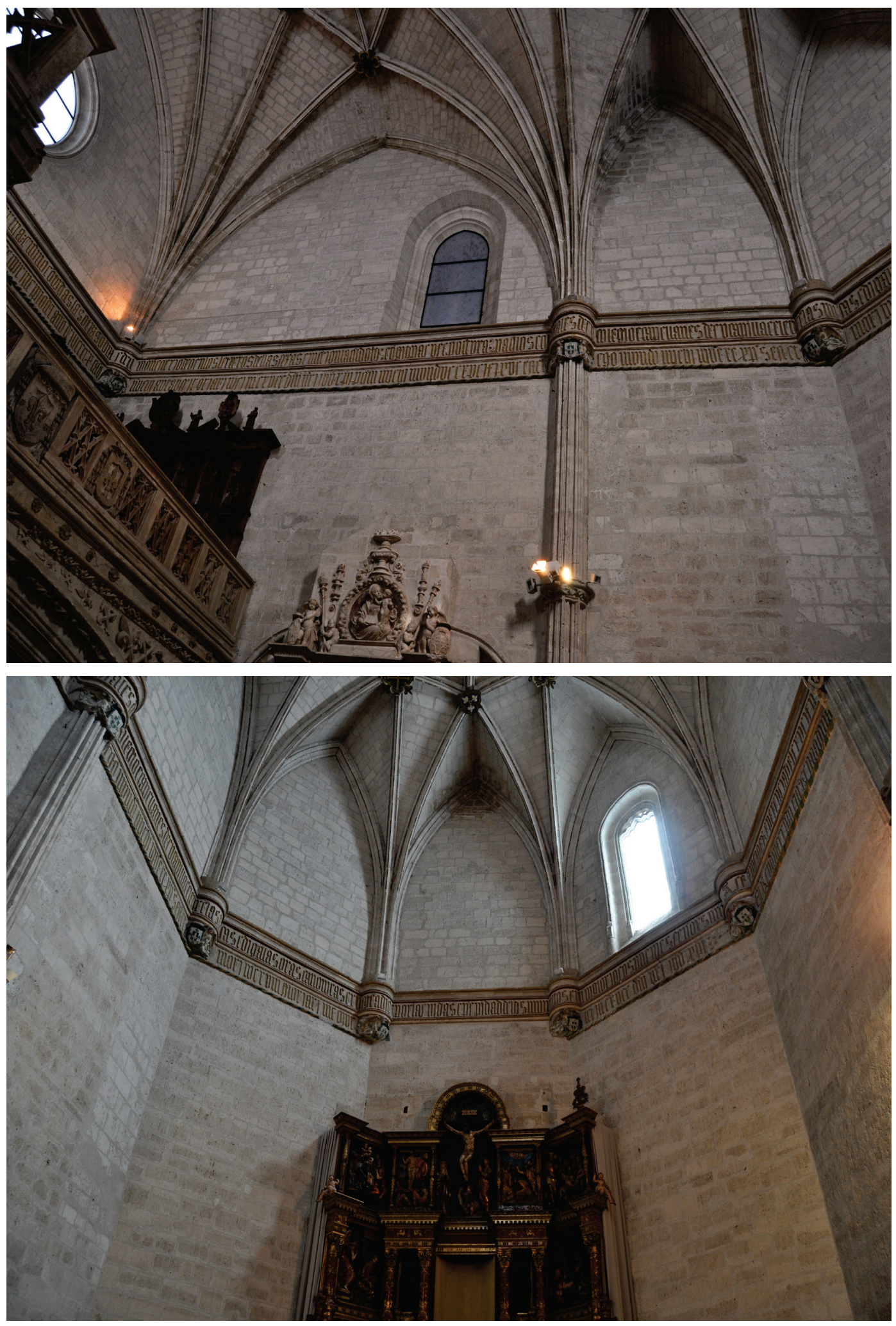
Francisco J. Molina DE LA TORRE

LOS ESTUDIOS EPIGRÁFICOS DESDE LA TEORÍA DE LA COMUNICACIÓN

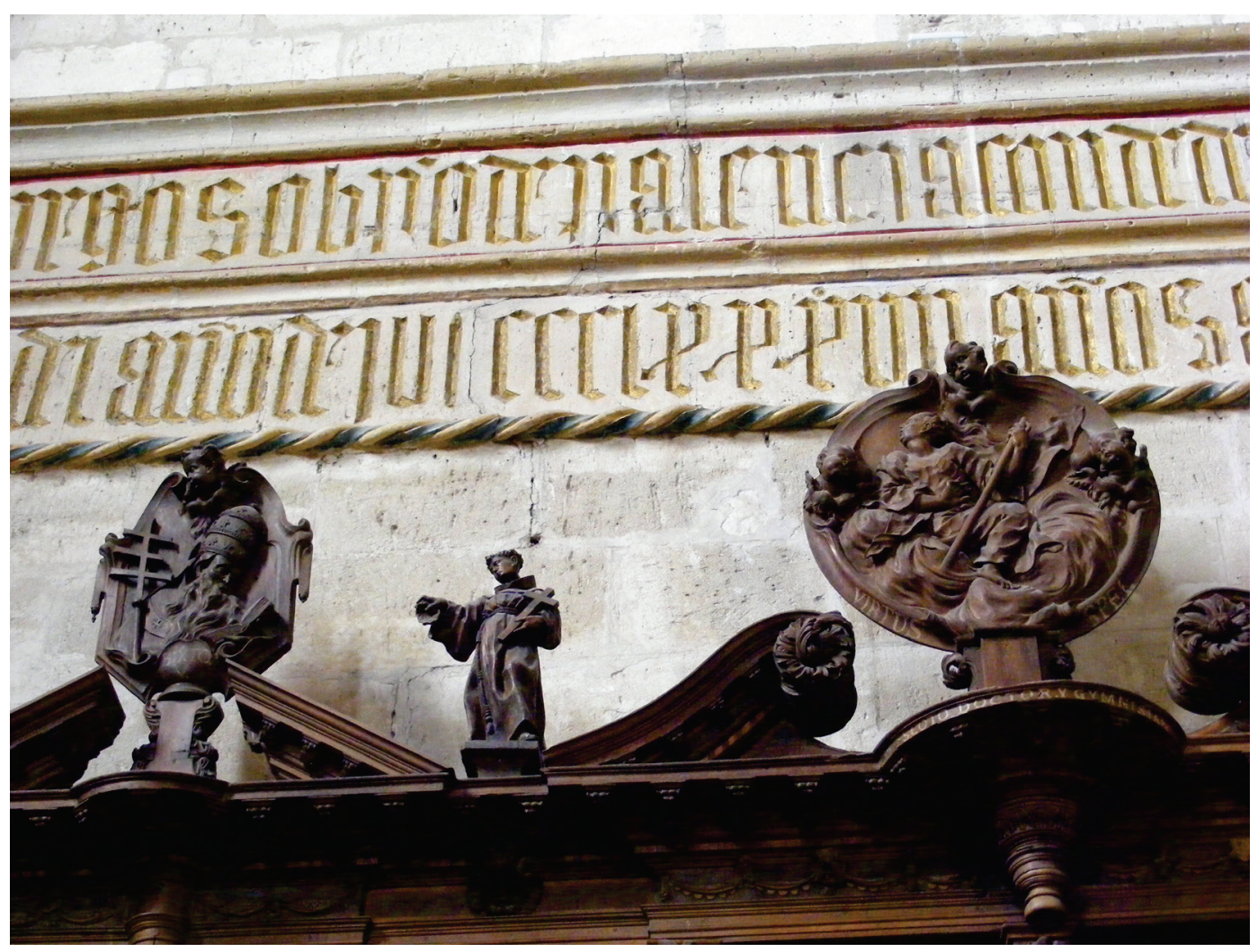

